\title{
Família em situação de vulnerabilidade social: uma questão de políticas públicas
}

\author{
Socially vulnerable families: a public issue
}

M ônica Araújo Gomes 1

M aria Lúcia Duarte Pereira 1

1 Universidade Estadual do Ceará.

Rua M onsenhor Bruno 810/702, M eireles, 60115-190, Fortaleza CE. monicagomes@secrel.com.br
Abstract The gravity situation of poverty and misery in Brazil is part of the constant worry and make to think about its social influence and, specially, on the family area, where the public politics still resent a more expressive action. To the poor family, designated by hunger and misery, home represents a place of privation, instability and family's links break and solidarity. This study aims to point out the vulnerability of the poor family that is not assisted by public politics being impeached to attend the basic necessities of their members, and support the profundity of the discussing about the construction of alternatives to the family empowerment. It is a field study, exploratory, based on the Social Representations Theory. The instruments used for the collection of data were: Free Association of W ords test and semi-structured interview. The results showed that family represents ambiguous feelings, of unity and disunity, associated with the image of lived up family and desired family constructed from the individuals' daily interaction; influencing and being influenced by the conflicting family relationships, conceived due to poverty that the families are submitted.

Key words Social exclusion, Family, Poverty, Public politics
Resumo A gravidade do quadro de pobreza e miséria, no Brasil, constitui permanente preocupação e obriga a refletir sobre suas influências no social e, principalmente, na área de atuação junto da família, na qual as políticas públicas ainda se ressentem de uma ação mais expressiva. Para a família pobre, marcada pela fome e pela miséria, a casa representa um espaço de privação, de instabilidade e de esgarçamento dos laços afetivos e de solidariedade. Este estudo tem como obj etivo apontar a vulnerabilidade da família pobreque, desassistida pelas políticas públicas, se vê impossibilitada de responder às necessi dades básicas de seus membros, e de favorecer 0 aprofundamento do debate acerca da construção de alternativas para o fortalecimento da família. Trata-se de um estudo de campo, exploratório, fundamentado na Teoria das Representações Sociais. Os instrumentos utilizados na coleta de dados foram: teste de Associação Livre de Palavras, e entrevista semiestruturada. Os resultados mostraram que "família" representa sentimentos ambivalentes, agregador/desagregador, associada à imagem de família real e sonhada construída a partir da interação dos sujeitos no seu cotidiano, influenciando e sendo influenciada por relações familiares conflituosas, geradas a partir da pobreza a que estão sujeitas as famílias.

Palavras-chave Exclusão social, Família, Pobreza, Políticas públicas 
A nova realidade não é saturada de possi bilidades. Ao contrário. É saturada de carência.

José de Souza M artins

\section{Introduzindo a questão}

Nos últimos vinte anos, várias mudanças ocorridas no plano socioeconômico-culturais, pautadas no processo de globalização da economia capitalista, vêm interferindo na dinâmica e estrutura familiar e possi bilitando alterações em seu padrão tradicional de organização.

Assim, não se pode falar de família, mas de famílias, para que se possa tentar contemplar a diversidade de relações que convivem na sociedade. No imaginário social, a família seria um grupo de indivíduos ligados por laços de sangue e que habitam a mesma casa. Pode-se considerar a família um grupo social composto de indivíduos que se relacionam cotidianamente gerando uma complexa trama de emoções. Entretanto, há dificuldade de se definir família, cujo aspecto vai depender do contexto sociocultural em que a mesma está inserida.

A família é, portanto, uma construção social que varia segundo as épocas, permanecendo, no entanto, aquilo que se chama de "sentimento de família" (A maral, 2001), que se forma a partir de um emaranhado de emoções e ações pessoais, familiares e culturais, compondo o universo do mundo familiar. Esse universo do mundo familiar éúnico para cada família, mas circula na sociedade nas interações com o meio social em que vivem.

Para Kaloustian \& Ferrari (1994), a família é o espaço indispensável para a garantia da sobrevivência e da proteção integral dos filhos e demais membros, independentemente do arranjo familiar ou da forma como vêm se estruturando. É a família que propicia os aportes afetivos e, sobretudo, materiais necessários ao desenvolvimento e bem-estar dos seus componentes. Ela desempenha um papel decisivo na educação formal e informal; é em seu espaço que são absorvidos os valores éticos e morais, e onde se aprofundam os laços de solidariedade. É também em seu interior que se constroem as marcas entre as gerações e são observados valores culturais. 0 que se afina com Sarti (1996) quando afirma que: A família não é apenas o elo afetivo mais forte dos pobres, o núcleo da sua sobrevivência material e espiritual, o instrumento através do qual viabilizam seu modo de vida, mas é o próprio substrato de sua identidade so- cial. Sua importância não é funcional, seu valor não é meramente instrumental, mas se refere à sua identidade de ser social e constitui o parâmetro simbólico que estrutura sua explicação do mundo.

Petrini (2003) acrescenta que no decorrer da evolução histórica, a família permanece como matriz do processo civilizatório, como condição para a humanização e para a socialização das pessoas. A educação bem-sucedida da criança na família é que vai servir de apoio à sua criatividade e ao seu comportamento produtivo quando for adulto. A família tem sido, é, e será a influência mais poderosa para o desenvolvimento da personalidade e do caráter das pessoas.

A família faz parte do universo de experiências (real e/ou simbólica) dos seres humanos no decorrer de sua história, do qual todos têm algo a dizer. Esta proximidade com a realidade defronta as pessoas com suas próprias questões familiares; toca em assuntos particularmente próximos à experiência pessoal de cada indivíduo e, por isso, são assuntos cheios de significados afetivos, além dos cognitivos. Família remete a lembranças, emoções, sentimentos, identidade, amor, ódio, enfim, um significado único para cada indivíduo, que, como ser biopsicossocial, está inserido no seu meio ambiente, integrando a cultura e o seu grupo social de pertença, o que leva a se estudar a família de modo contextualizado, considerando a subjetividade de cada ser.

Cada pessoa tem sua própria representação de família - da família real e da família sonhada, da sua família e da do outro - , representação esta ligada a concepções e opiniões, sentimentos e emoções, expectativas correspondidas ou não correspondidas. A família não é algo concreto, mas algo que se constrói a partir de elementos da realidade. Segundo Petrini (2003), a família encontra novas formas de estruturação que, de alguma maneira, a reconstituem, sendo reconhecida como estrutura básica permanente da experiência humana. Afirma ainda o autor que apesar da variedade de formas que assume ao longo do tempo, a família é identificada como o fundamento da sociedade.

U ma das provas mais evidentes da existência de uma família é o viver juntos sob o mesmo teto. I sto significa que a noção de casa implica compartilhar um determinado modo de vida, constituindo o que pode ser denominado de convivência familiar. Como afirma Sarti (1996), a família compreende a casa; a casa está, portanto, contida na família. Viver sob o mesmo teto, ao limitar o espaço da família, traz tam- 
bém em seu bojo a dimensão de sua complexidade, de seus encontros e desencontros; o fato de a família ser um espaço privilegiado de convivência não significa que não haja conflitos nesta esfera (Vicente, 1994).

0 estabelecimento de vínculos é próprio do ser humano, e a família, como grupo primário, é o locus para a concretização desta experiência. A confiança que o indivíduo tem de que pode estar no mundo e estar bem entre os outros lhe é transmitida pela sua aceitação dentro do grupo familiar. 0 sentir-se pertencente a um grupo, no caso, à família, possibilita-Ihe no decorrer de sua vida pertencer a outros grupos.

Para a família pobre, marcada pela fome e pela miséria, a casa representa um espaço de privação, de instabilidade e de esgarçamento dos laços afetivos e de solidariedade. Segundo Gomes (2003), quando a casa deixa de ser um espaço de proteção para ser um espaço de conflito, a superação desta situação se dá de forma muito fragmentada, uma vez que esta família não dispõe de redes de apoio para o enfrentamento das adversidades, resultando, assim, na sua desestruturação. A realidade das famílias pobres não traz no seu seio familiar a harmonia para que ela possa ser a propulsora do desenvolvimento saudável de seus membros, uma vez que seus direitos estão sendo negados.

\section{Pobreza e miséria no Brasil}

A gravidade do quadro de pobreza e miséria, no Brasil, constitui permanente preocupação e obriga a refletir sobre suas influências no social e, principalmente, na área de atuação junto da família, na qual as políticas públicas ainda se ressentem de uma ação mais expressiva. 0 Estado deve assegurar direitos e propiciar condições para a efetiva participação da família no desenvolvimento de seus filhos, porém os investimentos públicos brasileiros, na área social, estão cada vez mais vinculados ao desempenho da economia.

O Brasil nas últimas décadas vem impondo uma enorme desigual dade na distribuição de renda e el evados níveis de pobreza que exclui parte significativa de sua população do acesso a condições mínimas de dignidade e cidadania. Estudo apresentado pel o economista Dedecca (2003) mostrou que, de 1992 a 1999, os 25\% mais pobres perderam $20 \%$ da renda e os $5 \%$ mais ricos perderam $10 \%$. Estes dados levam a constatar que a defasagem salarial é maior para os pobres, o que amplia, ainda mais, a concentração de renda no Brasil.

Pobreza não pode ser definida de forma única, mas ela se evidencia quando parte da população não é capaz de gerar renda suficiente para ter acesso sustentável aos recursos básicos que garantam uma qualidade de vida digna. Estes recursos são água, saúde, educação, alimentação, moradia, renda e cidadania. De acordo com Yasbek (2003), são pobres aqueles que, de modo temporário ou permanente, não têm acesso a um mínimo de bens e recursos sendo, portanto, excluídos em graus diferenciados da riqueza social.

O termo exclusão social tem sentido temporal e espacial: um grupo social está excluído segundo determinado espaço geográfico ou em relação à estrutura e conjuntura econômica e social do país a que pertence. No Brasil, esse termo está relacionado principalmente à situação de pobreza, uma vez que as pessoas nessa condição constituem grupos em exclusão social, porque se encontram em risco pessoal e social, ou seja, excluídas das políticas sociais básicas (trabalho, educação, saúde, habitação, alimentação).

U m país tem pobreza quando existe escassez de recursos ou quando, apesar de haver um volume aceitável de riquezas, elas estão mal distribuídas. 0 Brasil não é um país pobre, e sim um país desigual. De acordo com estudo do Instituto de Pesquisa Econômica Aplicada I pea (Barros et al., 2000a), que analisa a pobreza, o Brasil ocupa o 9o lugar em renda per capita, dentre os países em desenvolvimento, mas cai para o 25o lugar quando se fala em proporção de pobres. Isto coloca o Brasil entre os países de alta renda e al ta pobreza. Ao mesmo tempo em que está entre os 10\% mais ricos, integra a metade mais pobre dos países em desenvolvimento, sendo um dos primeiros do mundo em desigualdade social. Aqui, $1 \%$ dos mais ricos se apropria do mesmo valor que os $50 \%$ mais pobres. Há no País 56,9 milhões de pessoas abaixo da linha de pobreza e destas, 24,7 milhões vivem em extrema pobreza (IBGE, 2003).

Os el evados níveis de pobreza que afligem a sociedade encontram seu principal determinante na estrutura da desigual dade brasileira uma perversa desigualdade na distribuição da renda e das oportunidades de inclusão econômica e social. A renda média brasileira é seis vezes maior que o valor definido como linha de indigência, ou seja, se a renda brasileira fosse igualmente distribuída, estaria garantido a cada pessoa seis vezes aquilo de que necessita para se alimentar (Barros et al, 2000a). 
Vive se no país, atualmente, um verdadeiro apartheid social (Véras, 2003), em que a estrutura de poder vigente é centrada em um modelo econômico que gera crescente riqueza para poucos e pobreza para muitos, e que garante e privilegia o crescimento da economia, sem uma política de renda justa e de atendimento às necessidades básicas da maioria da população.

As transformações ocorridas na política econômica do Brasil produziram profundas mudanças na vida econômica, social e cultural da população, gerando altos índices de desigualdade social. Como reflexo dessa estrutura de poder, acentuam-se as desigualdades sociais e de renda das famílias, afetando as suas condições de sobrevivência e minando as expectativas de superação desse estado de pobreza, reforçando sua submissão aos serviços públicos existentes. As desigualdades de renda impõem sacrifícios e renúncias para toda a família.

A situação de vulnerabilidade social da família pobre se encontra diretamente ligada à miséria estrutural, agravada pela crise econômica que lança o homem ou a mulher ao desemprego ou subemprego. Para Kaloustian e Ferrari (1994), por detrás da criança excluída da escola, nas favelas, no trabalho precoce urbano e rural e em situação de risco, está a família desassistida ou inatingida pela política oficial. Corroborando com este autor, M artins (1993) afirma que a criança abandonada é apenas a contrapartida do adulto abandonado, da família abandonada, da sociedade abandonada.

A proteção integral à criança e ao adolescente, garantida pelo Estatuto da Criança e do Adolescente - ECA (Brasil, 1990) em seu art. 4으, que tem a família, além da comunidade, da sociedade e do Poder Público, como uma das responsáveis pela proteção da sua prole, se vê, no entanto, no rumo inverso, uma vez que, alijada das mínimas condições socioeconômicas, sofre o processo da exclusão social. A injustiça social dificulta o convívio saudável da família, favorecendo o desequilíbrio das relações e a desagregação familiar.

Petrini (2003) afirma que à medida que a família encontra dificuldades para cumprir satisfatoriamente suas tarefas básicas de social ização e de amparo/serviços aos seus membros, criam-se situações de vulnerabilidade. A vida familiar para ser efetiva e eficaz depende de condições para sua sustentação e manutenção de seus vínculos.

A situação socioeconômica é o fator que mais tem contribuído para a desestruturação da família, repercutindo diretamente e de forma vil nos mais vulneráveis desse grupo: os filhos, vítimas da injustiça social, se vêem ameaçadose violados em seus direitos fundamentais. A pobreza, a miséria, a falta de perspectiva de um projeto existencial que vislumbre a melhoria da qualidade de vida, impõe a toda a família uma luta desigual edesumana pela sobrevivência.

As conseqüências da crise econômica a que está sujeita a família pobre precipitam a ida de seus filhos para a rua e, na mai oria das vezes, 0 abandono da escola, a fim de ajudar no orçamento familiar. Essa situação, inicialmente temporária, pode se estabelecer à medida que as articulações na rua vão se fortalecendo, ficando 0 retorno dessas crianças ao convívio sócio-familiar cada vez mais distante.

Percebe-se que para essa família, a perda ou rompimento dos vínculos produz sofrimento e leva 0 individuo à descrença de si mesmo, tornando-o frágil e com baixa auto-estima. Esta descrença conduz ainda o indivíduo a se desfazer do que pode haver de mais significativo para o ser humano: a capacidade de amar e de se sentir amado, incorporando um sentimento desagregador. A questão da família pobre aparece como a face mais cruel da disparidade econômica e da desigualdade social. Esse estado de privação de direitos atinge a todos de forma muito profunda, à medida que produz a banalização de sentimentos, dos afetos e dos vínculos, conforme ressalta Vicente (1994): 0 ser humano é complexo e contraditório, ambivalente em seus sentimentos e condutas, capaz de construir e de destruir. Em condições sociais de escassez, de privação e de falta de perspectivas, as possibilidades de amar, de construir e de respeitar o outro ficam bastante ameaçadas. $\mathrm{N}$ a medida em que a vida à qual está submetido não o trata enquanto homem, suas respostas tendem à rudeza da sua mera defesa da sobrevivência.

Ao aprofundar a discussão sobre família, pôde-se fazer um retrato vivo dos reflexos que a crise econômica impõe sobre as famílias pobres. Diante das reflexões apresentadas é possível afirmar que a situação de esgarçamento dos vínculos familiares resulta da miserabilidade a que estão sujeitas as famílias, sendo esta a mola propulsora para a sua desestruturação.

Faz-se necessário ressaltar a urgência da mudança de paradigma em relação à implementação de programas sociais mais conseqüentes e que visualizem sempre a família como alvo, não descontextualizando seus membros. Não dá para falar em políticas públicas 
eficazes sem se dar destaque à família como potencializadora destas ações. Ajudar a família mostra-se a única possibilidade de a se sociedade desenvolver dignamente.

\section{Material e método}

Trata-se de um estudo de campo, exploratório, fundamentado na Teoria das Representações Sociais (TRS). Basear este estudo nas TRS implicou aceitar que o sentido atribuído a um determinado objeto é uma construção psicossocial do indivíduo (M oscovici, 2003) e leva em sua bagagem, além de sua história pessoal, a história do grupo ao qual pertence. Compreender a significação de família, a partir das representações sociais salientadas nas falas dos sujeitos, significa avançar com um olhar mais abrangente; énecessário ir além dos limites que o problema aparenta impor, situando-o no seu contexto social.

- Campo de estudo: a pesquisa foi desenvolvida no Albergue, vinculado ao Pólo Central de A tendimento, unidade da Secretaria da A ção Social, localizado no centro da cidade de Fortaleza-Ceará que acolhe adolescentes em situação derua.

- Sujeitos: adolescentes na faixa etária de 12 a 18 anos incompletos, do sexo masculino efeminino, freqüentadores do Albergue no período de julho/2001 a julho/2002, e suas famílias (pai ou mãe consangüíneo).

- Amostra: para o teste de Associação Livre de Palavras a amostra foi composta por 20 adolescentes e 20 famílias totalizando em 40 sujeitos, já para a entrevista semi-estruturada, a amostra foi definida por saturação teórica, ficando composta por 15 adolescentes e 16 famílias, totalizando em 31 sujeitos.

- Instrumentos e procedimentos de coleta dos dados: foi aplicado o teste de Associação Livre de Palavras, tendo como estímulo a solicitação: "diga quatro palavras que Ihe lembre família". Em seguida foi realizada uma entrevista semiestruturada, tendo como pergunta de partida: 0 que é família para você?

- Análise e tratamento dos dados: para os dados apreendidos no teste de Associação Livre de Palavras foi utilizada a Análise Fatorial de Correspondência $(A F C)$ com base no programa Tri-Deux-M ots (versão 2.2), (Cibois, 1998). Para as informações levantadas a partir das entrevistas lançou-se mão da Análise de Conteúdo (AC) temática apoiada nos pressupostos de Bardin (1977).

\section{Delineando caminhos para o fortalecimento da família}

É fato, na sociedade brasileira, a crise do Estado resultante da dificuldade do País de acompanhar o desenvolvimento do novo cenário econômico internacional, tornando-se incapaz de garantir o crescimento econômico e solucionar questões sociais.

Essa crise materializa-se na vida de grande parte da população que é atingida diretamente pela ineficácia ou inexistência de políticas públicas: são hospitais sem condições de atendimento; são escolas públicas funcionando em condições precárias, com professores mal remunerados; são famílias desassistidas, morando em favelas sem saneamento básico e tampouco o mínimo de condições de uma vida humanamente decente; são milhares de crianças e adolescentes que buscam, nas ruas, sua sobrevivência, como resultado da inexistência de programas de assistência social eficazes e contínuos, que permitam uma estabilidade social a essa população carente.

Para Guareschi (2000): Pobreza, fome, misé ria, violência e exploração ainda são significantes poderosos a construir nossas sociedades. Enquanto tais, eles resistem e perpetuam uma ordem social que deve ser radicalmente questionada. Questionada quanto às suas condições históricas de produção e reprodução, quanto aos efeitos catastróficos que produz na vida de centenas de miIhares de pessoas e também quanto aos seus efeitos simbólicos.

É imprescindível ter em mente que esse sistema de desigualdade e má distribuição de renda destrói não só as famílias, mas toda a sociedade. Percebe-se, na verdade, que a questão fundamental é a necessidade de promoção e apoio às famílias vulneráveis através de políticas sociais bem articuladas e focalizadas. 0 reconhecimento das mesmas, como objeto de políticas públicas, constitui fator decisivo para atingir objetivos prioritários do desenvolvimento humano, tais como a minimização da pobreza, o acesso à educação, saúde, alimentação, moradia e proteção integral às suas crianças e adolescentes.

Barros et al (2000b) ressalta que o Brasil, no limiar do século 21, não é um país pobre, mas um país extremamente injusto e desigual, com muitos pobres. A desigualdade encontra-se na origem da pobreza e combatê-la torna-se um imperativo. Imperativo de um projeto de sociedade que deve enfrentar o desafio de combinar 
democracia com eficiência econômica e justiça social.

Diante da ausência de políticas de proteção social à população pauperizada, em conseqüência do retraimento do Estado, a família é chamada a responder por esta deficiência sem receber condições para tanto. 0 Estado reduz suas intervenções na área social e deposita na família uma sobrecarrega que ela não consegue suportar tendo em vista sua situação de vulnerabilidade socioeconômica.

O poder público precisa pautar suas políticas públicas na idéia de erradicação da pobreza, pois se percebe que as atenções, hoje voltadas à família, são extremamente conservadoras, inerciais, só justificáveis no contexto da cultura tutelar dominante (Carvalho, 1995).

U ma visão aproximada da situação de pobreza, embora parcial e localizada, pode ser obtida através da mensuração da desigualdade de renda e riqueza entre os indivíduos, que dá uma idéia do apartheid social existente no país onde milhões de brasileiros são mantidos fora da produção, consumo e cidadania.

A Pesquisa $N$ acional por Amostra de D omicílio - PNAD/2002 (IBGE, 2003) revelou que o País melhorou em seus indicadores sociais, mas que, na média, empobreceu por conta da conjuntura econômica. Desde 1998 a renda média do brasilei ro está em queda. Ela despencou de $\mathrm{R} \$ 714,00$ (setecentos e catorze reais) para $\mathrm{R} \$$ 668,00 (seiscentos e sessenta e oito reais) em 1999, R\$ 656,00 (seiscentos e cinqüenta e seis reais) em 2001 e chegou a $R \$ 635,00$ (seiscentos e trinta e cinco reais) em 2002. N este último ano, a renda dos mais pobres caiu mais rapidamente do que a dos mais ricos e isso levou ao aumento da desigualdade. A remuneração média real das pessoas com rendimento de trabaIho apresentou baixa de 2,5\% de 2001 para 2002. Este rendimento de 2002 teve queda de 12,3\% em relação ao de 1996, ano em que alcançou seu ponto máximo no período de 1992 a 2002.

Além da distribuição de renda, outro fator de desigualdadeé a educação. A educação tem 0 impacto de perpetuação do ciclo de pobreza entre gerações, uma vez que os pais com baixa escolaridade têm dificuldade em garantir um maior nível de escolaridade para seus filhos. Segundo dados da PNAD/2002 (IBGE, 2003), a taxa de anal fabetismo das pessoas de 10 anos ou mais de idade no ano de 2002 foi de 10,9\%. Complementando este "ciclo maldito" ressaltase 0 aumento do trabalho infantil, provavel- mente em decorrência da constante queda na renda das famílias eaumento do desemprego.

Diante dos dados apresentados é possível afirmar que a situação de esgarçamento dos vínculos familiares resulta da miserabilidade a que estão sujeitas as famílias. Esses dados também podem auxiliar na reflexão sobre a importância do debate acerca da família pobre e nos desafios que as políticas públicas têm para o enfrentamento desta problemática. 0 Estado deve pensar em políticas públicas de caráter universalistas, que assegurem proteção social e que reconheça a família como sujeito de direitos, capaz de potencializar as ações propostas.

As políticas sociais muito pouco têm contribuído para amenizar as condições de vulnerabilidade da família pobre, no entanto, há de se fazer referência ao Programa Saúde da Família - PSF, do M inistério da Saúde (Brasil, 2002) como estratégia em termos de política pública que centrou seu foco na família. O PSF tem como unidade de atendimento a família em seu habitat e prevê ações que levem em conta a possibilidade de detectar no domicílio as necessidades de suporte e incrementar estratégias comunitárias, no sentido de ampliar redes de apoio social. Com atenção contínua e ativa, desenvolve ações de promoção, proteção e recuperação da saúde dos indivíduos e da família de forma integral e contínua, objetivando com isso melhorar a qualidade de vida dos indivíduos.

Espera-se, portanto, que a família seja enfocada de forma concreta na agenda política dos governos para que ela possa prover sua autonomia e para que seus direitos sejam respeitados. É necessário que as políticas públicas venham em apoio à família pobre não apenas em relação à renda, mas também em relação ao acesso a bens e serviços sociais.

Alguns princípios precisam ser considerados ao se propor políticas de atendimento à família, tais como:

- Romper com a idéia de família sonhada e ter a família real como alvo. A família pode ser fonte de afeto e também de conflito, o que significa considerá-la um sistema aberto, vivo, em constante transformação.

- Olhar a família no seu movimento, sua vulnerabilidade e sua fragilidade, ampliando o foco sobre a mesma.

- Trabalhar com a escuta da família, reconhecendo sua heterogeneidade.

- Não olhar a família de forma fragmentada, mas trabalhar com o conjunto de seus mem- 
bros; se um membro está precisando de assistência, sua família estará também.

- Centrar as políticas públicas na família, re conhecendo-a como potencializadora dessas ações e como sujeito capaz de maximizar recursos.

- O Estado não pode substituir a família; portanto a família tem de ser ajudada.

- Não dá para falar de políticas públicas sem falar em parceria com a família.

Sabe-se, enfim, que há muito ainda o que se refletir sobre a situação da família no contexto sociopolítico atual e o caminho élongo, mas este pode ser o primeiro passo...

\section{Colaboradores}

M Gomes foi a responsável pela redação do texto, condução e análise da pesquisa; e M L Duarte, pela orientação do referencial teórico e revisão do texto.

\section{Referências bibliográficas}

Amaral CCG 2001. Família às avessas: gênero nas relações familiares de adolescentes. Ed. UFC, Fortaleza.

Bardin L 1977. Análise de conteúdo. Ed. 70, Lisboa.

Barros RP, H enriques R \& M endonça R 2000a. A estabilidade inaceitável: desigualdade e pobreza no Brasil, pp. 21-47. In R Henriques (org.). D esigualdade e pobreza no Brasil. Instituto de Pesquisa Econômica Aplicada - I pea, Rio de Janeiro.

Barros RP, Henriques R \& M endonça R 2000b. Desigualdade e pobreza no Brasil: retrato de uma estabilidade inaceitável. Revista Brasileira de Ciências Sociais 15(42):123-142.

Brasil 2002. Programa Saúde da Família. Revista Brasileira de Saúde da Família ano II: 7-17.

Brasil 1990. Estatuto da Criança e do Adolescente. Lei Federal no 8.069/90. Ministério da Justiça, Brasília, DF.

Carvalho M CB 1995. A priorização da família na agenda da política social, pp. 11-21. In M CB Carvalho (org.). A família contemporânea em debate. Ed. Cortez, São Paulo.

Cibois P 1998. Programa Tri-Deux-M ots. (Versão 2.2). Ed. UFR-Sciences Sociales, Paris.

Dedecca CS 2003. Anos 90: a estabilidade com desigualdade, pp. 109-139. In M A Santana \& JR Ramalho (orgs.). Além da fábrica: trabalhadores, sindicatos e a nova questão social. Ed. Boitempo, São Paulo.

Gomes M A 2003. Filhos de ninguém? U m estudo das representações sociais sobre família de adolescentes em situação de rua. Dissertação de mestrado. U niversidade Estadual do Ceará, Fortaleza.

Guareschi P 2000. Introdução, pp.17-25. In P Guareschi \& S Jovchelovitch (orgs.). Textos em representações sociais. (6a ed.). Ed.Vozes, Petrópolis.
IBGE 2003. Pesquisa Nacional por Amostra de Domićlios PNAD: síntese de indicadores 2002. IBGE, Rio de Janeiro.

Kaloustian SM \& Ferrari M 1994. Introdução, pp. 11-15. In SM Kaloustian (org.). Família brasileira, a base de tudo. Ed. Cortez-Unicef, São Paulo-Brasília.

M artins JS (org.) 1993. 0 massacre dos inocentes: a criança sem infância no Brasil. (2a ed.). Ed. Hucitec, São Paulo.

M oscovici S 2003. Representações sociais: investigações em psicologia social. Trad. de P Guareschi. Ed. Vozes, Rio de Janeiro.

Petrini JC 2003. Pós-modernidade e família. Ed. Edusc, Bauru.

Sarti C 1996. A família como espelho: um estudo sobre a moral dos pobres. Ed. Autores Associados, Campinas.

Véras M PB 2003. Prefácio à edição brasileira, pp. 13-29. In S Paugam. D esqualificação social - ensaio sobre a nova pobreza. Trad. de C Giorgetti \& T Lourenço. Ed. Cortez/Educ, São Paulo.

Vicente CM 1994. 0 direito à convivência familiar e comunitária: uma política de manutenção do vínculo, pp. 47-59. In SM Kaloustian (org.). Família brasileira, a base detudo. Ed. Cortez-Unicef, São Paulo-Brasília. Yazbek M C 2003. Classes subalternas e assi stência social. (4ạ ed.). Ed. Cortez, São Paulo.

Artigo apresentado em 7/05/2004

Aprovado em 17/06/2004

Versão final apresentada em 25/08/2004 